\title{
Identification and Functional Analysis of Temperate Siphoviridae Bacteriophages of Acinetobacter baumannii
}

\author{
Shimaa Badawy ${ }^{1,2}$, Maria I. Pajunen ${ }^{1}{ }^{\circledR}$, Johanna Haiko ${ }^{3}$, Zakaria A. M. Baka ${ }^{2}$, \\ Mohamed I. Abou-Dobara ${ }^{2}$, Ahmed K. A. El-Sayed ${ }^{2}$ and Mikael Skurnik $1,3, *$ (D) \\ 1 Department of Bacteriology and Immunology, Medicum, Human Microbiome Research Program, Faculty of \\ Medicine, University of Helsinki, 00014 UH Helsinki, Finland; shimaa_a_badwy@yahoo.com (S.B.); \\ maria.pajunen@helsinki.fi (M.I.P.) \\ 2 Department of Botany and Microbiology, Faculty of Science, Damietta University, 34511 New Damietta, \\ Egypt; zakariabaka@du.edu.eg (Z.A.M.B.); aboudobara@du.edu.eg (M.I.A.-D.); \\ akaelsayed@du.edu.eg (A.K.A.E.-S.) \\ 3 Division of Clinical Microbiology, Helsinki University Hospital, HUSLAB, 00290 Helsinki, Finland; \\ johanna.haiko@hus.fi \\ * Correspondence: mikael.skurnik@helsinki.fi; Tel.: +358-2941-26464
}

Received: 17 April 2020; Accepted: 29 May 2020; Published: 31 May 2020

\begin{abstract}
Acinetobacter baumannii is an opportunistic pathogen that presents a serious clinical challenge due to its increasing resistance to all available antibiotics. Phage therapy has been introduced recently to treat antibiotic-incurable $A$. baumannii infections. In search for new $A$. baumannii specific bacteriophages, 20 clinical $A$. baumannii strains were used in two pools in an attempt to enrich phages from sewage. The enrichment resulted in induction of resident prophage(s) and three temperate bacteriophages, named vB_AbaS_fEg-Aba01,vB_AbaS_fLi-Aba02 and vB_AbaS_fLi-Aba03, all able to infect only one strain (\#6597) of the 20 clinical strains, were isolated. Morphological characteristics obtained by transmission electron microscopy together with the genomic information revealed that the phages belong to the family Siphoviridae. The ca. $35 \mathrm{~kb}$ genomic sequences of the phages were $>99 \%$ identical to each other. The linear ds DNA genomes of the phages contained $10 \mathrm{nt}$ cohesive end termini, 52-54 predicted genes, an attP site and one tRNA gene each. A database search revealed an $>99 \%$ identical prophage in the genome of A. baumannii strain AbPK1 (acc. no. CP024576.1). Over $99 \%$ identical prophages were also identified from two of the original 20 clinical strains (\#5707 and \#5920) and both were shown to be spontaneously inducible, thus very likely being the origins of the isolated phages. The phage vB_AbaS_fEg-Aba01 was also able to lysogenize the susceptible strain \#6597 demonstrating that it was fully functional. The phages showed a very narrow host range infecting only two A. baumannii strains. In conclusion, we have isolated and characterized three novel temperate Siphoviridae phages that infect A. baumannii.
\end{abstract}

Keywords: Acinetobacter baumannii; temperate; bacteriophage; Siphoviridae; genome; att site; prophage; cohesive ends

\section{Introduction}

Acinetobacter baumannii is a Gram-negative non-fermenting aerobic coccobacillus that plays a significant role in infecting patients admitted to hospitals [1,2]. A. baumannii is a relatively newly emerged pathogen, notorious for its role as prominent causative agents of nosocomial wound as well as community-acquired infections [3]. A. baumannii has become a challenge for modern medicine due to being one of the most important multiple-drug resistant (MDR) nosocomial pathogens. The antibiotic 
resistance mechanisms of $A$. baumannii include enzymatic inactivation of the drugs, modification of the drug target site, and active efflux or decreased influx of drugs [4]. Thus, the control and therapeutic management of $A$. baumannii has becomes a pressing concern [4-6]. Pan-resistant strains, resistant to all available antibiotics, have been encountered [7]. Carbapenems (imipenem and meropenem) and colistin (polymyxin B) antibiotics are the last resort for treatment of Gram-negative bacterial infections; but resistant strains have been widely reported in clinical settings [8,9]. Due to this threat, phage therapy has been considered, and already used, as an alternative treatment to manage infections caused by MDR pathogens $[10,11]$, also recently in animals $[12,13]$ and humans $[14,15]$ against infections caused by MDR A. baumannii.

Bacteriophages (phages) are viruses that infect and reproduce in bacteria. The use of phages as therapeutic agents was initiated after their discovery by Frederick Twort in 1915 and Felix d'Herelle in 1917, where after, phages were used to treat a variety of bacterial infections all over the world [16,17]. Phages are highly host-specific [18], and their taxonomy is based on their morphology as well as on their nucleic acid $[19,20]$. Phages fall into two main classes.

- Virulent (lytic) phages follow the lytic infection cycle in which the phage overtakes the bacterial cell, reproduces itself at the expense of the host, and finally lyses and kills the host cell to release its progeny to the environment. This ability is the cornerstone of phage therapy [21].

- Temperate phages may enter the lysogenic cycle in which the phage genome integrates into the host genome using the activity of phage-encoded integrase, and the resulting bacteria are called lysogens. The integrated phage is called a prophage, it replicates as part of the host genome, and stays dormant for extended periods of time, due to the activity of a specific repressor that prevents the expression of the phage lytic cycle genes. The prophage may become induced and turn on the lytic cycle genes when the lysogen encounters adverse environmental conditions. The stress triggers the SOS (emergency) response, and the overexpression of proteases causes the degradation of the phage repressor thereby turning on the lytic cycle. The archetype of temperate phages is phage lambda [22].

Temperate phages which enter lysogeny maintain a long-term association with their host bacteria if they produce a mutually beneficial interaction that support efficient reproduction of both phages and bacteria [23]. The phages integration into the host genome is a crucial step in the lysogenic cycle and is mediated by the integrase protein, a DNA recombinase encoded by bacteriophages, at a distinct bacterial genome attachment site $(a t t B)$, which is identical to an attachment site $(a t t P)$ of the prophage genome [23]. Prophages do not integrate randomly into the host genomes. For example, prophages encoding a tyrosine integrase are usually integrated next to their host tyrosine tRNA gene and the palindromic structures of those temperate phages allow their integration within the bacterial genome [24].

Temperate phages are natural vectors for gene transmission among bacteria owing to their ability to integrate as prophages, and, consequently, affect the fitness and phenotype of the produced lysogen [25]. Several virulence factor or toxin encoding genes of pathogenic bacteria have been associated with prophages, indicating that temperate phages may play a significant role in increasing the host pathogenicity, on the other hand, a virulence-attenuating role is not often reported for temperate phages [26,27].

Whole genome sequences of several A. baumannii strains have revealed that they are polylysogenic, i.e., they harbor multiple integrated prophages [28]. Some prophages provide their host bacteria beneficial traits that increase the host fitness [29], some encode virulence factors including toxins that may benefit host pathogenesis [30] or antibiotic tolerance [31]. Prophages also protect the host bacteria against infection by other phages [32]. Resistance and other bacterial virulence elements are contained on highly mobile pieces of DNA that can easily spread to other bacteria. Prophages are one of the facilitators of this form of horizontal gene transfer, and have been discovered very often in bacterial genomes, offering advantageous features to the host. Prophages are claimed to be 
one of the major causes behind the evolution of A. baumannii pathogenicity [33]. Also remarkably, A. baumannii prophages encode for multiple putative virulence factors that may be implicated in the bacterium's capacity to colonize host niches, prevent the host immune system, survive in unfavorable environments, and tolerate antibiotics. Overall the results point towards a significant contribution of prophages for the spreading and evolution of pathogenicity in A. baumannii, and highlight their clinical relevance [33].

Some phage therapy trials have failed in the past apparently due to lack of knowledge on phage biology and due to use of uncharacterized phages [34]. Therefore, there is still room for more studies to provide greater understanding of phage biology to avoid failures in phage therapy [35]. In our search for new A. baumannii specific bacteriophages we isolated three temperate bacteriophages with a very narrow host range belonging to the family Siphoviridae. The ca. $35 \mathrm{~kb}$ genomes were $>99 \%$ identical to each other, contained $10 \mathrm{nt}$ cohesive end termini, 52-54 predicted genes, an attP site and one tRNA gene each. We also present data that the phages were induced from two of the clinical strains used for the search and that one of the phages was able to lysogenize a susceptible strain demonstrating that it was fully functional.

\section{Materials and Methods}

\subsection{Bacterial Strains, Media and Growth Conditions}

The clinical A. baumannii and other bacterial strains used in this study (Table S1) originated from diverse patient samples (wound, tissue, sputum, broncho-alveolar lavage, trachea, pleural fluid, urine, bile, blood, rectum and drainage and intravenous catheters) isolated at Department of Bacteriology, University of Helsinki and Helsinki University Central Hospital (HUSLAB), Helsinki, Finland. The A. baumannii strain DSM 106838 (storage number \#6597, Table S1) was received from DSMZ, the German Collection of Microorganisms and Cell Cultures $\mathrm{GmbH}$. The bacteria were grown with shaking at $220 \mathrm{rpm}$ in lysogeny broth (LB) [36] medium at $37^{\circ} \mathrm{C}$ overnight (16-24 h). Luria agar (LA) plates contained LB supplemented with $1.5 \%$ agar and soft agar contained LB supplemented $0.4 \%$ agar. All strains were stored in tryptic soy broth containing $20 \%$ glycerol at $-80^{\circ} \mathrm{C}$. The strains are identified in the text by their storage numbers (Table S1).

\subsection{Bacteriophage Isolation and Propagation}

Enrichments of Acinetobacter specific bacteriophages were carried out as described [37] with some modifications. Twenty clinical A. baumannii strains were grown separately at $37^{\circ} \mathrm{C}$ for $16 \mathrm{~h}$ and $100 \mu \mathrm{L}$ of each culture was combined into two sets of parallel pools with 10 strains each. One $\mathrm{mL}$ of a sterile-filtered $(0.45 \mu \mathrm{m})$ sewage filtrates was mixed with each pair of pools to which $9 \mathrm{~mL}$ of LB was added. These pooled enrichment cultures were incubated overnight on a rocking platform at $37^{\circ} \mathrm{C}$ to allow enrichment of any Acinetobacter-specific phages present. To each $3 \mathrm{~mL}$ portion of the enrichment cultures $0.2 \mathrm{~mL}$ of chloroform was added to kill and lyse the bacteria, and the mixture was shaken for $20 \mathrm{~min}$ at room temperature (RT). The chloroform-treated lysates were then clarified by centrifugation at $5000 \mathrm{rpm}$ for $10 \mathrm{~min}$ at $4{ }^{\circ} \mathrm{C}$, and the supernatants filtered through $0.45 \mu \mathrm{m}$ filters (Minisart ${ }^{\circledR}$ Sartorius, Göttingen, Germany) to remove bacterial cells. The obtained lysates were then stored at $4{ }^{\circ} \mathrm{C}$ for bacteriophage isolation.

\subsection{Bacteriophage Titration by Droplet and Double-Agar Overlay Methods}

One hundred $\mu \mathrm{L}$ of indicator bacteria $\left(\mathrm{OD}_{600} \sim 1.0\right)$ was mixed into $3 \mathrm{~mL}$ of molten soft agar (adjusted to $50^{\circ} \mathrm{C}$ ) and immediately poured on warm LA plates. The soft agar was allowed to solidify at RT for $20 \mathrm{~min}$. The enrichment lysates or phage suspensions to be tested were serially 10 -fold diluted in SM buffer ( $50 \mathrm{mM}$ Tris-HCL, $100 \mathrm{mM} \mathrm{NaCl}, 8 \mathrm{mM} \mathrm{MgSO} \cdot \cdot 7 \mathrm{H}_{2} \mathrm{O}, 0.01 \%$ gelatin, $\mathrm{pH}$ 7.5). Five $\mu \mathrm{L}$ droplets of the undiluted and diluted suspensions were pipetted on the solidified soft agar plates that 
were incubated overnight at $37^{\circ} \mathrm{C}$. The plates were observed for the presence of bacterial lysis under the droplets to indicate the presence of phages [38].

For double-agar overlay titration method appropriate dilutions of the phage suspension, estimated based on the droplet titration results, were prepared to contain 50-500 plaque forming units (PFU) per $50 \mu \mathrm{L}$. The $50 \mu \mathrm{L}$ phage aliquots and $100 \mu \mathrm{L}$ of indicator bacteria $\left(\mathrm{OD}_{600} \sim 1.0\right)$ were pipetted into $3 \mathrm{~mL}$ of $50^{\circ} \mathrm{C}$-adjusted soft agar, carefully mixed and poured on LA plates. After overnight incubation the individual plaques were enumerated and the original phage titers (PFU/mL), calculated based on the plaque numbers and the dilution factors [18,39].

\subsection{Plaque Purification}

Individual plaques on double-agar overlay plates were used for plaque purification of individual phages. A well-isolated single plaque was punched out using a sterile Pasteur pipette and transferred to an Eppendorf tube containing $500 \mu \mathrm{L}$ of SM buffer and $50 \mu \mathrm{L}$ of chloroform. The tube was shaken for $20 \mathrm{~min}$ at RT, centrifuged at $11,000 \times \mathrm{g}$ for $10 \mathrm{~min}$ at $4{ }^{\circ} \mathrm{C}$, and $300 \mu \mathrm{L}$ of the water phase was transferred to a new Eppendorf tube that was kept cap open in a laminar-flow safety cabinet to evaporate the residual chloroform. The phage concentration was titrated, and single plaque purification was repeated from new double agar overlay plates at least five times to ensure purity of each phage [40].

\subsection{Preparation of Phage Stocks}

Phage stocks were prepared from semiconfluent soft agar plates prepared using appropriately diluted purified phage solutions. Plates were incubated overnight, and $3 \mathrm{~mL}$ of SM buffer was added on the semiconfluent lawn of plaques and incubated at RT for $30 \mathrm{~min}$ on a rocking platform. The soft agar and the buffer were collected into a 15-mL polypropylene (PP) tube, and the remaining soft agar was recovered by repeating the procedure. Two hundred $\mu \mathrm{L}$ chloroform was added to every $3 \mathrm{~mL}$ of the combined soft agar samples, the tubes were mixed for 15-20 min at RT, and centrifuged at 5000 8 for $10 \mathrm{~min}$ at $4{ }^{\circ} \mathrm{C}$. The supernatant was filtered through a $0.45-\mu \mathrm{m}$ filter (Minisart ${ }^{\circledR}$ Sartorius) into a sterile $15-\mathrm{mL}$ PP tube, and $40 \%$ sucrose was added to final concentration of $8 \%$. The obtained stocks were titrated and stored at $4{ }^{\circ} \mathrm{C}[41,42]$.

\subsection{Phage Purification from Liquid Lysates}

Large scale lysates of phages were prepared in $500 \mathrm{~mL}$ cultures. A. baumannii strain \#6597 (Table S1) served as a host strain for the propagation of phages. Phages were precipitated from the lysate according to [43] with some modifications. DNase I and RNase were added, each to final concentration of $1 \mu \mathrm{g} \mathrm{mL}^{-1}$, to the lysate that was incubated for $30 \mathrm{~min}$ at RT. Solid $\mathrm{NaCl}(29.2 \mathrm{~g})$ was dissolved into the lysate ( $1 \mathrm{M}$ final concentration) that was incubated on ice for $1 \mathrm{~h}$ prior centrifugation at $11,000 \times g$ for $10 \mathrm{~min}$ at $4{ }^{\circ} \mathrm{C}$ to remove bacterial debris. PEG-8000 was slowly stirred into the supernatant to a final concentration of $10 \%$ at RT after which the solution was incubated at least $1 \mathrm{~h}$ at $4{ }^{\circ} \mathrm{C}$ to precipitate the phage particles. The precipitated phages were pelleted by centrifugation at $11,000 \times g$ for 10 minutes at $4{ }^{\circ} \mathrm{C}$. After carefully removing all liquid from the centrifuge bottles, the phage pellet was resuspended gently into $8 \mathrm{~mL}$ SM buffer. To remove residual PEG, the suspension was extracted thrice with an equal volume of chloroform followed by centrifugation at $3000 \times \mathrm{g}$ for $15 \mathrm{~min}$ at $4{ }^{\circ} \mathrm{C}$. The phage preparations were further purified by discontinuous glycerol density gradient ultracentrifugation through $5 \%$ and

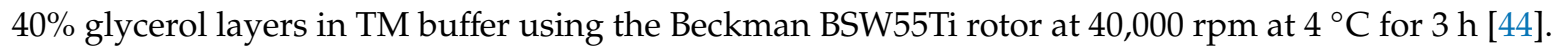
The phage pellet was resuspended in SM buffer containing $8 \%$ sucrose.

\subsection{Transmission Electron Microscopy}

A $3 \mu \mathrm{L}$ drop of purified high-titer $\left(10^{10}-10^{13} \mathrm{PFU} / \mathrm{mL}\right)$ phage in $0.1 \mathrm{M}$ ammonium acetate, $\mathrm{pH} 7.0$, concentrated using a $10^{5}$ Da cut-off Vivaspin ultrafiltration (Minisart ${ }^{\circledR}$ Sartorius), was deposited on carbon-coated 400 mesh copper grid and allowed to adsorb for $1 \mathrm{~min}$, followed by $2 \%$ uranyl acetate for $30 \mathrm{~s}$ [45]. Samples were examined with a JEOL JEM-1400 transmission electron microscope JEOL 
Ltd., Tokyo, Japan) under $80 \mathrm{kV}$ at the electron microscopy unit (Institute of Biotechnology, University of Helsinki, Helsinki, Finland). Pictures were taken using Gatan Orius SC 1000B bottom-mounted charged coupled device (CCD)-camera (Gatan Inc., Pleasanton, CA, USA). The dimensions of at least 10 phage particles measured to calculate the average and standard error values.

\subsection{Phage Adsorption Assay}

Adsorption is the first step of phage infection of host bacteria. Approximately $3 \times 10^{5} \mathrm{PFU}$ in $100 \mu \mathrm{L}$ was mixed with a $500 \mu \mathrm{L}$ of $A$. baumannii strain \#6597 grown to $\mathrm{OD}_{600} \sim 1-1.2$ in $\mathrm{LB}$, and to a control tube with $500 \mu \mathrm{L}$ sterile LB. The tubes were incubated at $37^{\circ} \mathrm{C}$ and at different time points $(1,5$, $10,15,20,25$, and $30 \mathrm{~min}$ ) the tubes were centrifuged at $16,000 \times g$ for $3 \mathrm{~min}$ and the supernatants placed immediately on ice until titrated for non-adsorbed phages. The phage titers were compared to that of the control supernatant set as $100 \%$. Each assay was performed in duplicate and repeated for 3 times.

\subsection{Phage Host Range Determination}

The host specificity of the phages was determined by the droplet titration method (described above) on 91 strains (Table S1) including 21 A. baumannii, 18 A. pittii, one A. calcoaceticus, one A. junii, three $A$. lwoffii, three $A$. nosocomialis, two $A$. radioresistens, three $A$. ursingii, one Acinetobacter sp, 24 Escherichia coli, 10 Staphylococcus aureus, two Pseudomonas aeruginosa, one Yersinia pseudotuberculosis and one Klebsiella pneumoniae strain(s). Positive droplet test results were confirmed by the double-layer method using appropriately diluted phage preparations.

\subsection{Phage and Bacterial DNA Extraction}

Phage DNA isolation was performed from $10^{10}-10^{13} \mathrm{PFU} / \mathrm{mL}$ phage preparations using the phenol-chloroform extraction method [43] with some modifications. Briefly, to $400 \mu \mathrm{L}$ of the phage suspension $1.3 \mu \mathrm{L}$ DNase I (1 U/ $\mu \mathrm{L}$, Promega, Madison, WI, USA) and $4 \mu \mathrm{L}$ RNase A $(1 \mathrm{mg} / \mathrm{mL})$ were added and the mix was incubated $30 \mathrm{~min}$ at $37^{\circ} \mathrm{C}$ to degrade bacterial DNA and RNA. Then, 16 $\mu \mathrm{L}$ of $0.5 \mathrm{M}$ EDTA, $1.2 \mu \mathrm{L}$ of proteinase $\mathrm{K}(20 \mathrm{mg} / \mathrm{mL})$, and $20 \mu \mathrm{L} 10 \%$ SDS were added to the tube that was incubated at $56{ }^{\circ} \mathrm{C}$ for at least $1 \mathrm{~h}$. The cooled suspension was extracted sequentially with a volume of phenol, phenol/chloroform (1/1) and chloroform, each time mixing the tube gently for $15 \mathrm{~min}$, followed by $5 \mathrm{~min}$ centrifugation at $16,000 \times \mathrm{g}$. The nucleic acid was precipitated from the final aqueous phase by adding 0.1 volumes of $3 \mathrm{M}$ sodium acetate $\mathrm{pH} 5.2$, and 2 volumes of absolute ethanol. The tube was mixed manually for 2-3 min until the precipitated DNA thread became visible, and could be transferred using a $1 \mu \mathrm{L}$ inoculation loop into a tube containing $1 \mathrm{~mL} 70 \% \mathrm{EtOH}$. After 10 min centrifugation at RT, the supernatant was carefully removed and the pellet was air dried and dissolved overnight into 50-100 $\mu \mathrm{L}$ of TE buffer (10 mM Tris-HCL, 1 mM EDTA, pH 8.0). In the case that the DNA thread failed to form, the DNA was pelleted by centrifugation, and washed with $1 \mathrm{~mL}$ of $70 \% \mathrm{EtOH}$ as above. The isolation and purification of the genomic DNA from bacterial strains was accomplished using JetFlex Genomic DNA Purification Kit (Thermo Fisher Scientific, Waltham, MA, USA) following the manufacturer's instructions. The quality and quantity of the DNA was estimated using the NanoDrop spectrophotometer (ND-1000, Wilmington, DE, USA) and/or the Qubit machine (Invitrogen Qubit 2.0 Fluorometer, CA, USA) applying the QubitTM dsDNA BR Assay Kit (Thermo Fisher Scientific), followed by visualization by agarose gel electrophoresis [40].

\subsection{Genome Sequencing, Assembly and Bioinformatics Based on Sequence Analysis}

The genomic DNA of the phages and of the bacterial strains was sequenced at Eurofins Genomics (https://www.eurofinsgenomics.eu/) using Illumina HiSeq with 150-bp paired-end reads. The DNA was fragmented using sonication into 300-600 bp fragments that were then processed to generate DNA libraries. The obtained sequence reads were assembled de novo using the A5-miseq pipeline [46]. The read coverage of the resulting contigs were checked with the Artemis software $[47,48]$ and the contaminating bacterial genomic sequences identified by their $>100$-fold lower read coverages (the read 
coverage of the phage contig was $>10,000$ ) and BLASTN searches. To verify the fidelity of the assemblies, the reads were mapped back to the de novo assembled contigs using the Geneious (Biomatters Ltd., Auckland, New Zealand) prime R10 software version 2019.0.4. tools [49]. Preliminary annotation of the phage genomes were carried out using rapid annotation subsystems technology (RAST) [50] that was manually checked and revised with the Artemis software $[47,48]$. The PhageTerm program was used to identify the termini of the phage genomes [51]. The identities and functions of the predicted genes and gene products were analyzed using the BLASTP (https://blast.ncbi.nlm.nih.gov/Blast) and HHpred [52] servers. Different EMBOSS sequence analysis tools were used through the Chipster platform [53] at the Centers for Scientific Computing (https://www.csc.fi/). The multiple sequence alignment program MAFFT was used to compare phage genome sequences [54]. The phylogentic trees were constructed using the Molecular Evolutionary Genetic Analysis Software, Version X (MEGA X), where the neighbor-joining statistical tree analysis method was used. The number of bootstrap replications was set at 1000. The Poisson substitution model was used within the MEGA X software [55]. The phage and prophage whole genome sequence phylogenetic tree was constructed using the VIrus Classification and Tree building Online Resource (VICTOR) [56]. The A. baumannii strain multilocus sequence types (MLST) were determined using the PubMLST web service (https://pubmlst.org/abaumannii/) and the $\mathrm{O}-$ and K-serotypes using the Kaptive service [57].

\subsection{PCR and Sanger Sequencing}

The PCR primers (Table S2) were designed using the EMBOSS Eprimer3 tool in Chipster [53], and commercially synthetized at Metabion International AG (Steinkirchen, Germany). The PCRs were performed in $0.2 \mathrm{~mL}$ thin walled PCR tubes (4titude ${ }^{\circledR}$ Ltd, Wotton, UK), in a total volume of $25 \mu \mathrm{L}$ containing $1 \mu \mathrm{L}$ of DNA template, $0.2 \mu \mathrm{M}$ of each primer (Table S2), $200 \mu \mathrm{M}$ of dNTP mix (Thermo Fisher Scientific), $2.5 \mu \mathrm{L}$ of 10× Standard Taq Reaction Buffer and 1.25 U of Taq DNA Polymerase (Thermo Fisher Scientific). The PCR cycling included an initial denaturation at $95^{\circ} \mathrm{C}$ for $3 \mathrm{~min}$, followed by 34 cycles each consisting of denaturation at $95^{\circ} \mathrm{C}$ for $30 \mathrm{~s}, 30 \mathrm{~s}$ at annealing temperature, and extension for $30 \mathrm{~s}$ at $72{ }^{\circ} \mathrm{C}$. This was followed by a final extension step at $72{ }^{\circ} \mathrm{C}$ for 5 min after which PCR products were kept on hold, at $4{ }^{\circ} \mathrm{C}$, until further processing. The annealing temperatures were calculated using the net service at https://www.thermofisher.com/. The PCR products were analyzed using 1\% agarose gel electrophoresis and cleaned using the Nucleospin Gel extraction and PCR clean-up kit (Macherey-Nagel GmbH, Düren, Germany). The purified PCR fragments were sequenced with appropriate sequencing primers using the Sanger sequencing service at the Institute for Molecular Medicine Finland (https://www.fimm.fi/en/services/technology-centre/sequencing).

\subsection{Restriction Endonuclease Analysis}

Restriction digestions were carried out using the restriction enzymes EcoRI, HincII, NsiI, PstI, SalI, ScaI, SexAI, and SpeI (Thermo Fischer Scientific). These enzymes gave several well separated bands when in silico digested by the NEBcutter (http://nc2.neb.com/NEBcutter2/). The digestions were carried out in a final volume of $10 \mu \mathrm{L}$, containing DNA (ca. $300 \mathrm{ng}$ ), $0.5 \mu \mathrm{L}$ of enzyme and $1 \mu \mathrm{L}$ of Fast digest green buffer $\left(10 \times\right.$, Thermo Fisher Scientific). After $2-16 \mathrm{~h}$ incubation at $37^{\circ} \mathrm{C}$ the restriction fragments along with undigested DNA and GeneRuler $1 \mathrm{~kb}$ DNA Ladder (Thermo Fisher Scientific) were loaded on $1 \%(w / v)$ agarose gel including $0.005 \%(w / v)$ Midori green. After the electrophoresis the fragments were visualized using UV transillumination and images recorded using the BioRad GelDoc $\mathrm{XR}+$ imaging system.

\subsection{Lysogenization Experiment}

To test the ability of the phages to form lysogens, phage resistant colonies were isolated and prophage inductions were performed as described [58] with some modifications. The prophage-free A. baumannii strain \#6597 was used as a host for the lysogenization test [59]. Bacterial suspension was spread on LA plate, allowed to dry for a while, and $10 \mu \mathrm{L}$ drops of phage stock were pipetted on the 
bacterial lawn. After $48 \mathrm{~h}$ incubation at $37^{\circ} \mathrm{C}$, ten surviving colonies were selected randomly from within the lysis zones, further tested for phage resistance. To confirm the integration of the phage genome, bacterial DNA isolated from the confirmed phage-resistant strains was used as template in phage-specific PCRs as described above.

\subsection{Prophage Induction Experiments}

Spontaneous prophage induction from A. baumannii strains \#5707 and \#5920 was carried out by inoculating a single colony from each strain separately in $5 \mathrm{~mL}$ of LB, incubating overnight at $37^{\circ} \mathrm{C}$. The culture was split into two and to one portion of the cultures, $0.2 \mathrm{~mL}$ of chloroform was added to kill and lyse the bacteria, and the mixture was shaken for $20 \mathrm{~min}$ at RT. The chloroform-treated lysates and non-treated cultures were then clarified by centrifugation at $5000 \mathrm{rpm}$ for $10 \mathrm{~min}$ at $4{ }^{\circ} \mathrm{C}$, and the supernatants filtered through $0.45 \mu \mathrm{m}$ filters (Minisart ${ }^{\circledR}$ Sartorius) to remove bacterial cells. The obtained samples were then stored at $4{ }^{\circ} \mathrm{C}$ for further experiments.

\subsection{Nucleotide Sequence Accession Numbers}

The annotated nucleotide sequences of the phage genomes were submitted to sequence databases under the following accession numbers: fEg-Aba01 (MT344103), fLi-Aba02 (MT344104) and fLi-Aba03 (MT344105). The raw sequence read data of A. baumannii strains \#5707, \#5907, \#5920 and \#6597 was deposited to NCBI sequence read archive under bioproject PRJNA625727, and received the accession numbers SRX8124491, SRX8124492, SRX8124492, and SRX8124494, respectively.

\section{Results}

\subsection{Phage Isolation and Phenotypic Characterization}

Enrichments were carried out in pools of ten clinical A. baumannii strains each and the obtained sterile-filtered pool-lysates were then tested for phages using each clinical A. baumannii strain individually as indicator bacteria in the soft agar plates. Phage activity was detected only against one of the strains, the A. baumannii strain \#6597 (Table S1). After several rounds of plaque purification from different lysates, three phages named vB_AbaS_fEg-Aba01, vB_AbaS_fLi-Aba02 and vB_AbaS_fLi-Aba03 (hereafter referred to as fEg-Aba01, fLi-Aba02 and fLi-Aba03, respectively) were obtained.

The three phages showed very similar plaque morphologies and formed round slightly turbid 1-1.5 mm diameter plaques with haloes on A. baumannii \#6597 (Figure S1). Transmission electron microscopy revealed that all the phages resemble morphologically Siphoviridae (Figure 1). The physical dimensions of the phages are listed in Table 1. The phages possess icosahedral capsids (58-63 nm in diameter) to which a long, flexible and non-contractile tail (136-156 nm in length and 8-9 $\mathrm{nm}$ in diameter) was attached (Table 1).

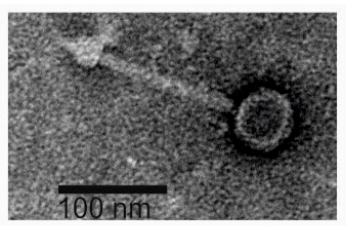

(a)

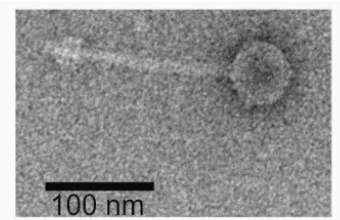

(b)

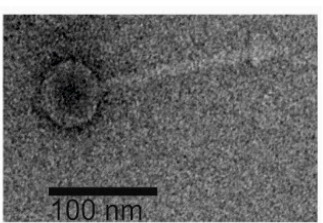

(c)

Figure 1. Transmission electron micrographs of fEg-Aba01 (a), fLi-Aba02 (b), and fLi-Aba03 (c). The phages were negatively stained with $2 \%$ uranyl-acetate. The scale bar is $100 \mathrm{~nm}$. 
Table 1. Phage particle and genome overview. Phage dimensions were measured by TEM and represent mean values for at least 10 measured phage particles.

\begin{tabular}{cccc}
\hline Bacteriophage & fEg-Aba01 & fLi-Aba02 & fLi-Aba03 \\
\hline Capsid size, $\mathrm{nm}$ & $58.4 \pm 4$ & $63 \pm 2$ & $58.6 \pm 5$ \\
Tail length, nm & $156 \pm 9$ & $136 \pm 1.8$ & $142 \pm 0.8$ \\
Tail width, nm & $10.8 \pm 0.3$ & $9 \pm 0.2$ & $8.5 \pm 0.9$ \\
Genome size, $\mathrm{bp}$ & 33,779 & 35,053 & 34,931 \\
GC content $(\%)$ & 40.1 & 40.2 & 40.1 \\
$n$ genes & 52 & 53 & 54 \\
$n$ tRNAs & 1 & 1 & 1 \\
\hline
\end{tabular}

Adsorption is the first decisive step of phage infection of host bacteria. The adsorption curves of the phages showed that the phages fEg-Aba01, fLi-Aba02 and fLi-Aba03 adsorbed extremely rapidly onto A. baumannii \#6597 bacteria. Within $1 \mathrm{~min}>98 \%$ of the free phage particles had already adsorbed to the host bacteria, and at 5 min nearly $100 \%$ were adsorbed (Figure 2).

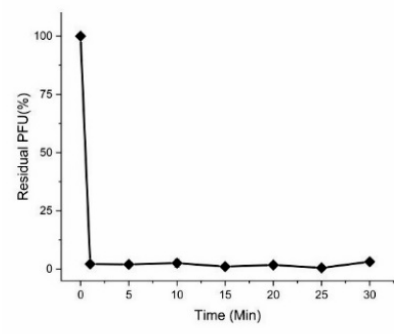

(a)

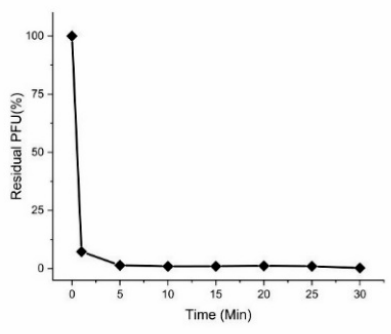

(b)

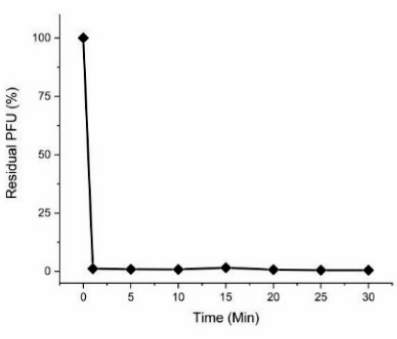

(c)

Figure 2. Adsorption curves of fEg-Aba01 (a), fLi-Aba02 (b), and fLi-Aba03 (c) to A. baumannii \#6597. The phage titer in the control supernatant was set to $100 \%$ and the residual titers at different time points were related to that. Each assay was performed in duplicate and repeated for 3 times. Note that the standard deviation bars are mostly hidden behind the symbols.

The host ranges of phages fEg-Abo01, fLi-Aba02 and fLi-Aba03 were tested with 91 strains representing 14 species (Table S1). The phages infected only the original A. baumannii host strain \#6597, and in addition, a recent MDR A. baumannii patient isolate, strain \#6898 (Table S1).

\subsection{Phage Genomic Characterization, Annotation and Comparison to Other Phages}

Each de novo assembly of the Illumina sequencing reads of the phages resulted in $>100$ contigs. While for each phage, one contig, 33-35 kb in size, had very high read coverage, the read coverage of the other contigs was low. In addition, as the BLASTN searches with the low-coverage contigs revealed that they represented $A$. baumannii genomic sequences, it is very likely that they represent host bacterial DNA sequences either as contaminants in the phage DNA samples or through transduction. Thus the high-coverage contigs represented the phage genomic sequences, and the low-coverage contigs were excluded from further study.

The three phage sequences were highly similar (>99\% identical) with each other, however, they showed no similarity to any phage genomes deposited in the sequence databases. The restriction digestion patterns of the three phages were almost identical (two shown in Figure S3). Comparison of the sequence-based and experimental restriction digestion patterns allowed rough mapping of the physical ends of the phage genomes, however, the PhageTerm analysis allowed exact identification of the ends, and it revealed that the three phages each contained $10 \mathrm{nt}$ long $3^{\prime}$-cohesive ends with identical sequences: 5'-CGCCCCCCAT-3' (Figure S4). To confirm the presence of the cohesive ends, EcoRI digested phage DNA was analyzed in agarose gel after heat treatment at $80^{\circ} \mathrm{C}$ and either cooled rapidly on ice or allowed to cool slowly to RT. The cohesive ends in the latter case annealed to each 
other and produced a visible larger band in the gel (Figure 3B). Based on these results the genome sequences were rearranged to represent the linear genomes in the phage particles and to locate the majority of the predicted genes to the forward direction. Finally, the experimental restriction enzyme digestions of the phage DNA were in perfect match with in silico restriction digestion fragment sizes (Figure $3 \mathrm{~A}$ ) that are as follows:

- $\quad \operatorname{EcoRI}(10231,8997,8427,2482,1196$ left end, 1150 right end, 604, 522, 170 bp)

- HincII (9559, 8170, 5179, 2713, 2546, 2074, 1228 right end, 767, 711, 496, 219, 117 left end)

- $\quad$ ssiI $(9006,8804,6595,3916,2482$ right end, 2104, left end, 872)

- $\quad \operatorname{PstI}(11219,5337,4003,3313,2405,2240,1474$ left end, 1295 right end, 912, 699, 444, 438)

- $\quad$ SaII (22168 right end, 11611 left end)

- $\quad$ ScaI (23619 right end, 10160 left end)

- SexAI (22976 right end, 10803 left end)

- $\quad$ SpeI (13517 left end, 7659, 5298, 2926, 2907, 1185, 287 right end)
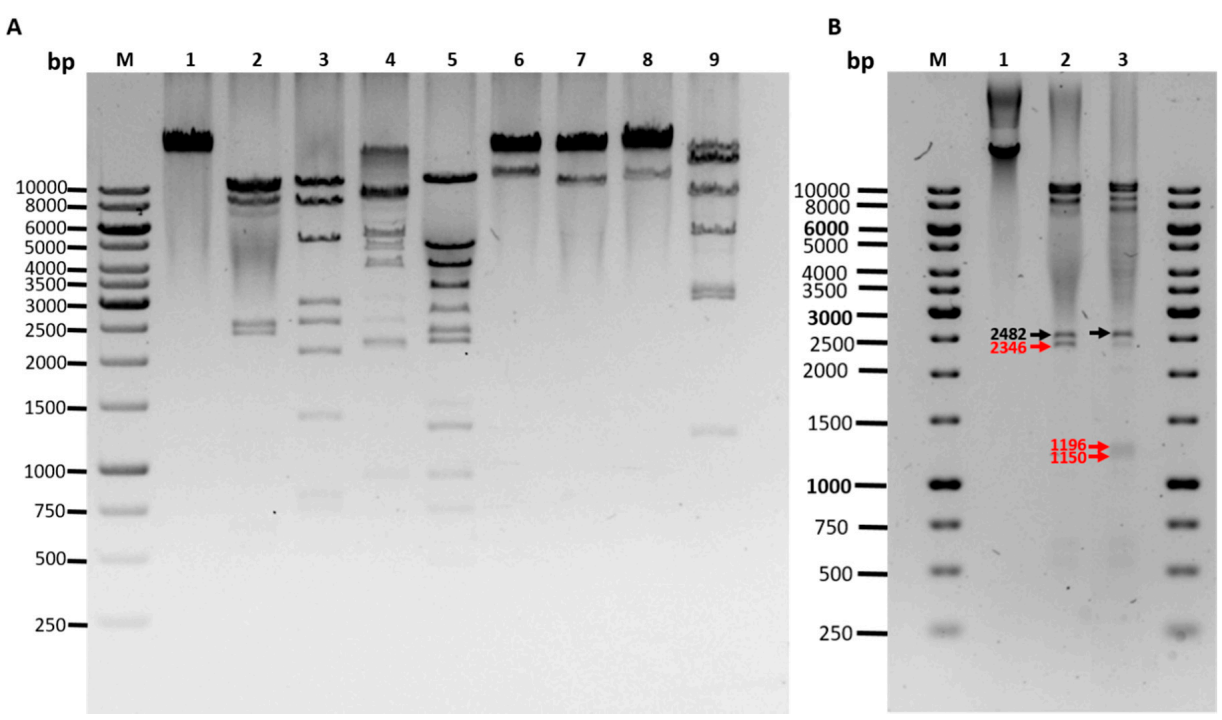

Figure 3. Agarose-gel-electrophoresis analysis of restriction enzyme digested fEgAba01 DNA. Panel (A) fEg-Aba01 genomic DNA digested with EcoRI (lane 2), HincII (lane 3), NsiI (lane 4), PstI (lane 5), SaII (lane 6), ScaI (lane 7), SexAI (lane 8), and SpeI (lane 9). Lane 1, undigested DNA. Lane M, 1-Kb DNA ladder. Panel (B), confirmation of the cohesive ends. Lanes: 1, undigested phage DNA; lane 2, EcoRI-digested DNA, the red arrow indicates the joint fragment; lane 3, EcoRI-digested phage DNA, heated after digestion at $80{ }^{\circ} \mathrm{C}$ for $15 \mathrm{~min}$, followed by rapid cooling to room temperature (RT). The red arrows indicate the left and right end EcoRI fragments. The black arrows indicate the $2482 \mathrm{bp}$ fragment.

Annotation of the sequences showed that fEg-Aba01 consisted of 52, fLi-Aba02, of 53, and fLi-Aba03, of 54, predicted genes (Table 1 and Table S3). Seven of the genes in each were encoded in the reverse strand. The GC contents of the phages were similar, 40.1-40.2\% (Table 1 ) that is very close to the GC content of A. baumannii host, ca. 39\% [60]. The overall organization of the genome of $\mathrm{fEg}-\mathrm{Aba} 01$ is presented in Figure 4.

While no similar phages were found from nucleotide sequence databases, a $99 \%$ identical $35 \mathrm{~kb}$ genomic island (GI5) annotated as a prophage is present in the A. baumannii strain AbPK1 genome (GenBank accession number CP024576.1). The AbPK1 strain was isolated as the causative agent of virulent epidemic pneumonia that killed hundreds of sheep on a farm in Pakistan [60]. In addition, the predicted CP14 prophage of three other A. baumannii strains (AB042, AB043 and ATCC17978, acc. no CP019034, CP043910, CP018664, respectively) showed 80\% identity to fEg-Aba01 [61]. 


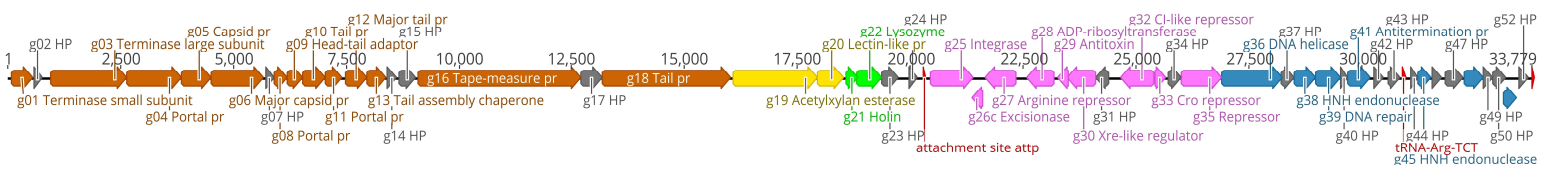

Figure 4. The annotated genome map of fEgAb01. The predicted genes are shown as colored arrows labelled with predicted functions (Genes encoding structural proteins, brown; lysogen functions, purple; nucleic acid enzymes, blue; hypothetical proteins, grey; tRNA gene and the 3'-cohesive end, red; lysis functions, green; carbohydrate interactions, yellow; for details see Table S3). The map was drawn with Geneious 10.2.6 (www.geneious.com). HP, hypothetical protein; pr, protein.

The predicted functions of the phage gene products, based on database searches, are shown in Table S3. A putative function could be assigned to ca. 30 gene products leaving 22 annotated as hypothetical proteins. Five functional groups were identified:

1. The lysogen decision gene clusters of the three phages were identified and the gene products annotated based on similarity searches (Table 2). The integrase (Gp25 in fEg-Aba01; Gp27 in fLi-Aba02 and fLi-Aba03) is 100\% identical in all three phages. It is the site-specific recombinase that by catalyzing recombination between the two DNA molecules results in either integration or excision of the prophage into and from the host chromosome [62]. The arginine (Gp27c; Gp29c) and the CI-like (Gp32c; Gp34c) repressors account for the establishment of lysogeny and the immunity of lysogens to superinfection. The production of CI represses the Cro (Gp33; Gp35) synthesis. The excisionase (Gp26c; Gp28c) binds to the integrase and enables it to reverse the integration process and liberate the prophage. The Xre family transcriptional regulator (Gp30c; Gp32c) and another repressor (Gp35; Gp37) may also be involved in the regulation of lysogeny/lysis decision. Traditionally, the lysogeny/lysis decision is regulated by the competition between CI repressor and Cro proteins for the occupancy of the operator (OR) region. The Cro protein binds to the OR and OL promotors and turns off the transcription of the CI repressor gene and thus allows transcription and translation of the lytic cycle and other late genes [63]. Some integrases are associated in the integration and excision of phage genomes, whilst others are essential for the maintenance of plasmid copy number or elimination of chromosomal dimers [64-66]. A phylogenetic tree of Acinetobacter site-specific integrase sequences was constructed (Figure 5). The results demonstrate that Gp25 integrase clusters among the bacteriophage Hp1-like tyrosine integrases in the XerC superfamily. The ADP-ribosyltransferase (Gp28c; Gp30c) and the antitoxin (Gp29c; Gp31c) may be a toxin-antitoxin pair stabilizing the lysogen [67]. The hypothetical protein (Gp31c; Gp33c) is similar to a A. baumannii protein that shares a fold with a cell division regulator protein of Streptococcus pneumonia GbsP [68] and may interact with the bacterial cell wall synthesis.

2. The DNA synthesis, regulation and replication gene products include the Xre family transcriptional regulator (Gp30c; Gp32c), the DNA helicase (Gp36; Gp38) that unwinds the DNA to create template for DNA replication [69], and another repressor (Gp35; Gp37) likely involved in gene regulation. The putative HNH endonucleases (Gp38, Gp45 and Gp51; Gp40, Gp47 and Gp53) may play a variety of roles in replication, recombination, and repair pathways [70]. Finally, the antiterminator protein (Gp41;Gp43) renders RNA polymerase resistant to termination signals [71].

3. The DNA packaging into the phage head is carried out by the terminase complex containing the small and large terminase subunits (Gp01 and Gp03, respectively). It recognizes the cos site, introduces there the nicks to generate the cohesive ends to the genome and separates the cohesive ends in a reaction requiring ATP hydrolysis [72]. The terminase and the phage portal proteins (Gp04, Gp08 and Gp11) are believed to be the initiators of the head assembly. The NinB homolog (Gp48; Gp50) may be associated in recombination.

4. The phage structural proteins are encoded by the genes encoded in the left half of the genome (Figure 4), and include Gp05 and Gp06 that are annotated as capsid and major capsid proteins, 
respectively, that initiate formation of the procapsid [73], Gp09 is the putative phage head-tail adaptor, Gp16, the tail length tape-measure protein, and Gp12, the major tail protein. Gp8 and Gp10 are also structural peorteins, and Gp18 (Gp20 in fLi-Aba02 and fLi-Aba03) is also predicted to be a tail component (Table S3). Gp13 is a putative tail assembly chaperone. The predicted tail length based on the tape measure protein of 1195 amino acid residues, $1.5 \AA$ per residue [74], would be ca $180 \mathrm{~nm}$, that is 20-30 nm longer than the measured tail lengths (Table 1). Perhaps the tape measure protein extends to the tip of the bulky tail baseplate omitted from the measures.

5. The host lysis protein holin is predicted to be Gp21 (Gp23 in fLi-Aba02 and fLi-Aba03), and Gp22 (Gp24 in fLi-Aba02 and fLi-Aba03), the lysozyme, involved in the bacterial lysis and release of the phage progeny [75]. The predicted peptidoglycan hydrolase (Gp19 in fLi-Aba02 and fLi-Aba03) encoding gene is not present in $\mathrm{fEg}-\mathrm{Aba01}$, actually, it is deleted and the $g 18$ in $\mathrm{fEg}-\mathrm{Aba01}$ is a fusion product containing $5^{\prime}$-end of gene $g 18$ and $3^{\prime}$-end of gene $g 20$ of fLi-Aba02 (Table S3). The acetylxylan esterase and lectin-like proteins (Gp19;Gp21 and Gp20;Gp21, respectively) are both carbohydrate-associated proteins and might have a function in degrading the bacterial capsule polysaccharides.

Table 2. The lysogen decision gene cluster in phages fEg-Aba01, fLi-Aba02, and fLi-Aba-03.

\begin{tabular}{|c|c|c|c|}
\hline Gene & Location & Predicted Function & Amino Acids \\
\hline g2 $5_{\text {fEg-Aba01 }}$ & $20438-21397$ & \multirow{3}{*}{ Integrase } & 319 \\
\hline $\mathrm{g} 27_{\mathrm{fLi}-\mathrm{Aba} 02}$ & $22436-21477$ & & 319 \\
\hline g27fLi-Aba03 & $22436-21477$ & & 319 \\
\hline $\mathrm{g} 26 \mathrm{c}_{\mathrm{fEg}}-\mathrm{Aba} 01$ & $21614-21363$ & \multirow{3}{*}{ Excisionase } & 83 \\
\hline $\mathrm{g} 28 \mathrm{c}_{\mathrm{fLi}}-\mathrm{Aba} 02$ & $22653-22402$ & & 83 \\
\hline g28c $\mathrm{c}_{\mathrm{fLi}} \mathrm{Aba} 03$ & 22653-22402 & & 83 \\
\hline $\mathrm{g} 2 \mathrm{c}_{\mathrm{fEg}} \mathrm{Aba} 01$ & $22353-21667$ & \multirow{3}{*}{ Arginine repressor } & 228 \\
\hline $\mathrm{g} 29 \mathrm{c}_{\mathrm{fLi}}-\mathrm{Aba} 02$ & 23392-22706 & & 228 \\
\hline g29 $\mathrm{c}_{\mathrm{fLi}-\mathrm{Aba} 03}$ & 23392-22706 & & 228 \\
\hline $\mathrm{g} 28 \mathrm{c}_{\mathrm{fEg}}-\mathrm{Aba} 01$ & 23182-22595 & \multirow{3}{*}{ ADP-ribosyltransferase } & 195 \\
\hline $\mathrm{g} 30 \mathrm{c}_{\mathrm{fLi}} \mathrm{Aba} 02$ & 24429-23392 & & 345 \\
\hline $\mathrm{g} 30 \mathrm{c}_{\mathrm{fLi}}-\mathrm{Aba} 03$ & $24267-23392$ & & 291 \\
\hline $\mathrm{g} 29 \mathrm{c}_{\mathrm{fEg}-\mathrm{Aba} 01}$ & $23494-23258$ & \multirow{3}{*}{ Antitoxin } & 78 \\
\hline $\mathrm{g} 31 \mathrm{c}_{\mathrm{fLi}-\mathrm{Aba} 02}$ & $24741-24505$ & & 78 \\
\hline g $31 c_{\text {fLi-Aba03 }}$ & $24579-24343$ & & 78 \\
\hline $\mathrm{g} 30 \mathrm{c}_{\mathrm{fEg}}-\mathrm{Aba} 01$ & $24113-23478$ & \multirow{3}{*}{$\begin{array}{c}\text { Xre family } \\
\text { transcriptional regulator }\end{array}$} & 211 \\
\hline $\mathrm{g} 32 \mathrm{c}_{\mathrm{fLi}} \mathrm{Aba} 02$ & $25360-24725$ & & 211 \\
\hline g32 $\mathrm{c}_{\text {fLi-Aba03 }}$ & $25198-24563$ & & 211 \\
\hline $\mathrm{g} 31 \mathrm{c}_{\mathrm{fEg}-\mathrm{Aba} 01}$ & $24406-24116$ & \multirow{3}{*}{ Hypothetical protein } & 96 \\
\hline g33 $c_{\text {fLi-Aba02 }}$ & $25653-25363$ & & 96 \\
\hline g $33 c_{\text {fLi-Aba03 }}$ & 25491-25201 & & 96 \\
\hline $\mathrm{g} 32 \mathrm{c}_{\mathrm{fEg}-\mathrm{Aba} 01}$ & $25397-24657$ & \multirow{3}{*}{ Repressor protein CI } & 246 \\
\hline $\mathrm{g} 34 \mathrm{c}_{\mathrm{fLi}}-\mathrm{Aba} 02$ & 26596-25904 & & 230 \\
\hline $\mathrm{g} 34 \mathrm{c}_{\mathrm{fLi}}-\mathrm{Aba} 03$ & $26434-25742$ & & 230 \\
\hline $\mathrm{g} 33_{\mathrm{fEg}-\mathrm{Aba} 01}$ & $25663-25421$ & \multirow{3}{*}{ Cro repressor } & 80 \\
\hline g35fLi-Aba02 & $26910-26725$ & & 61 \\
\hline $\mathrm{g} 35_{\mathrm{fLi}-\mathrm{Aba} 03}$ & $26748-26521$ & & 75 \\
\hline
\end{tabular}

Multiple genome alignment of the three phages and the prophage sequences of the A. baumannii strain AbPK1 (from CP024576.1) and those of strains \#5707 and \#5920 revealed several regions of differences (RoD) with overview in Table 3 and detailed illustration in Figure S5. The alignment demonstrates that all the genomes resemble closely each other (Figure S5A) and that local deletions/insertions/substitutions have taken place (Figure S5B). The RoD-02 deletion of $832 \mathrm{bp}$ 
in fEg-Aba01 deleted the predicted peptidoglycan hydrolase gene ( $g 19$ in fLi-Aba02) and generated the fusion gene $g 18$ in $\mathrm{fEg}-\mathrm{Aba01}$. Visual inspection of the RoDs (Figure S5B) also demonstrated that single nucleotide substitutions were mainly present in the AbPK1 prophage sequence (RoD-03, RoD-06 and RoD-08) suggesting that it is more distantly related to the others, this is also evident from the whole-genome phylogenetic tree (Figure S5A) where fEg-Aba01 is an outgroup and the other five sequences cluster together. Remarkably, the fLi-Aba02 was almost identical with the prophages of strains \#5707 and \#5920 while fLi-Aba03 differed from those only in RoD-06. The fEg-Aba01 genome differed from the others based on the deletions in RoD-01, RoD-02, RoD-05 and RoD-05 that all caused severe rearrangements.

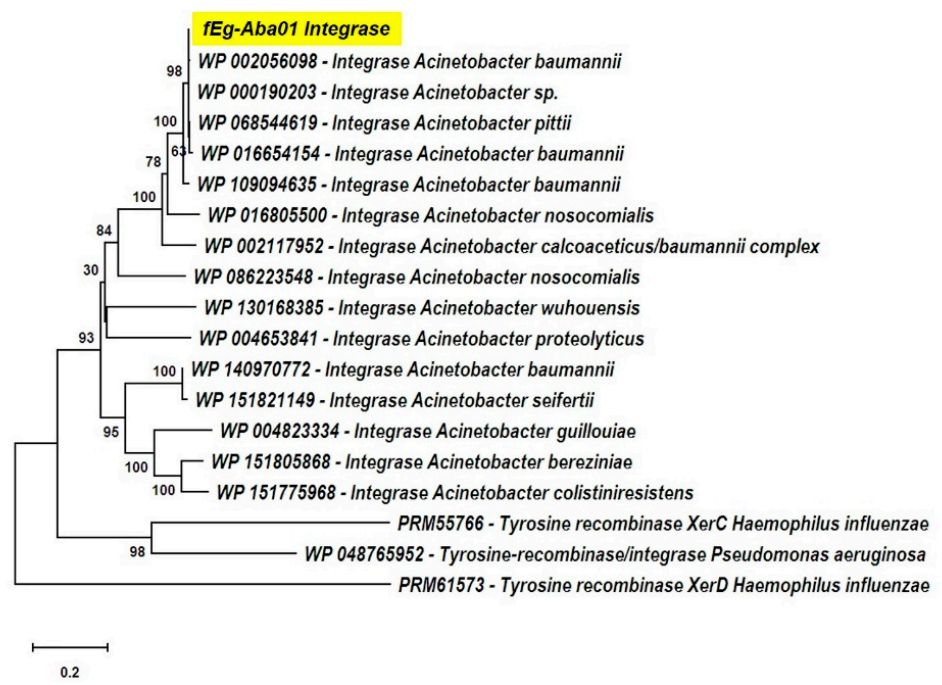

Figure 5. The phylogenetic tree of fEgAb01 integrase with different site-specific Acinetobacter integrases and rooted with the Haemophilus influenza and Pseudomonas aeruginosa integrases. The tree was constructed using the MEGA $X$ neighbor-joining statistical tree analysis method with bootstrapping set to 1000 tree branches are proportional to branch lengths. The branch labels represent bootstrap values. The integrase of $\mathrm{fEg}$.Aba01 is highlighted in yellow.

Table 3. The regions of differences ( $\mathrm{RoD})$ between the nucleotide sequences of the three temperate Acinetobacter phages and the prophage loci of A. baumannii strains AbPK1, \#5707 and \#5920. See Figure S5 for details.

\begin{tabular}{cll}
\hline $\begin{array}{c}\text { Region of } \\
\text { Difference }\end{array}$ & Location in fEg-Aba01 & \multicolumn{1}{c}{ Description } \\
\hline RoD-01 & 18065..18066 & $\begin{array}{l}\text { A 207 bp in-frame deletion in } g 20 \text { of } \\
\text { fEg-Aba01 that causes a } 69 \text { amino acid } \\
\text { truncation of Gp20. }\end{array}$ \\
& $\begin{array}{l}\text { A } 832 \text { bp deletion in fEg-Aba01 that } \\
\text { generates a fusion of genes corresponding } \\
\text { to g18 and g20 of phages fLi-Aba02 and } \\
\text { fLi-Aba03. The deletion includes the gene } \\
\text { g19 of the latter. }\end{array}$ \\
\hline RoD-02 & $\begin{array}{l}\text { Five nucleotide substitutions in a stretch of } \\
13550 . .13551 \text { bp within } g 10 \text { of AbPK1 prophage } \\
\text { causing one (Arg-to-Lys) neutral } \\
\text { substitution. }\end{array}$ \\
\hline
\end{tabular}


Table 3. Cont.

\begin{tabular}{|c|c|c|}
\hline $\begin{array}{l}\text { Region of } \\
\text { Difference }\end{array}$ & Location in $\mathrm{fEg}-\mathrm{Aba} 01$ & Description \\
\hline RoD-04 & 32618 & $\begin{array}{l}\text { A silent one nucleotide substitution in } g 50 \\
\text { of fEg-Aba01 }\end{array}$ \\
\hline RoD-05 & $32453 . .32454$ & $\begin{array}{l}\text { A } 67 \text { bp deletion in } g 50 \text { of fEg-Aba01 } \\
\text { causing a frame shift mutation and } \\
\text { truncating the } 3 \text { '-end of } g 48\end{array}$ \\
\hline RoD-06 & 24177 & $\begin{array}{l}\text { A one bp substitution in gene } g 32 c \text { causing a } \\
\text { Ser to Phe substitution in the AbPK } 1 \text { protein }\end{array}$ \\
\hline RoD-07 & 22613..22772 & $\begin{array}{l}\text { A stretch of three variants of } 27 \mathrm{bp} \\
\text { repetitions (6-13 repetitions) in the } 3^{\prime} \text { end of } \\
\text { gene } g 28 \mathrm{c} \text {. Also out of frame deletions in } \\
\text { the fEg-Aba01 gene causing frame shift and } \\
3^{\prime} \text {-end truncation. Identical full length } \\
\text { region is present in fLi-Aba02, and the } \\
\# 5707 \text { and \#5920 prophages }\end{array}$ \\
\hline RoD-08 & 21103 & $\begin{array}{l}\text { A silent one bp substitution in the integrase } \\
\text { gene } g 27 \text { of } A b P K 1 \text { prophage }\end{array}$ \\
\hline
\end{tabular}

\subsection{Prophage Lysogenic Characteristics}

This suggested that the origin of the phages could be a prophage in any of the twenty clinical A. baumannii strains used in the enrichment experiment. To this end we designed two phage-specific primer pairs to detect the presence of the putative prophages by PCR and used the isolated DNA from each of the twenty clinical A. baumannii strains as template. Phage genome DNA was used as a positive control. Three strains (\#5707, \#5907 and \#5920) gave strong positive PCR results with both primer pairs (Table S4).

To confirm these results the genomic DNA of these strains together with strain \#6597 were sequenced and the obtained raw read data was used in de novo assembly, and the reads were also mapped directly to the three phage genomes used as references. These results confirmed that the strains \#5707 and \#5920, but not \#5907, carried the whole prophage (Figure S6). Based on the whole genome sequence data the MLST, capsular (K) and lipo-oligosaccharide (LOS) types were determined for the strains (Table 4). These data shows that the prophage-positive strains \#5707 and \#5920 are very similar as they both have the same MLST, and LOS and capsule types. The other two strains differ from the two and from each other. BLASTN alignment of the sequence data of the strains against the prophage locus of AbPK1 (Figure S5) shows that strain \#5907 carries a truncated prophage genome while the prophage sequences are completely absent from strain \#6597. The truncated prophage corresponds to AbPK1 nucleotides from 2546100 to 2560500 (acc. no. CP024576.1), explaining the positive $700 \mathrm{bp}$ PCR result for this strain (Table S4). Interestingly though, the location of the truncated prophage sequences of \#5907 were not the same where the prophage is located in AbPK1.

Table 4. Whole genome sequence data based overview of A. baumannii strains.

\begin{tabular}{lllll}
\hline Strain & MLST & LOS-Type & K-Type & Prophage \\
\hline$\# 5707$ & 1114,1841 & OCL1 & KL25 & Yes \\
$\# 5907$ & 1806,208 & OCL1 & KL2 & Partial \\
$\# 5920$ & 1114,1841 & OCL1 & KL25 & Yes \\
$\# 6597$ & 1816,195 & OCL1 & KL3 & No \\
AbPK1 & 452 & OCL1 & KL3 & Yes \\
\hline
\end{tabular}

In a population of lysogenic bacteria a few at times enter the lytic cycle and phages are released in small quantities into the growth medium. To detect this experimentally the clinical strains \#5707 and 
\#5920 were grown in liquid medium to stationary phase. The presence of strain \#6597 specific phages was detected from the culture supernatants of both lysogenic strains confirming that the strains very likely were the origin of the phages (data not shown).

The presence of the prophage in the genomic sequences of the three A. baumannii strains, i.e., of AbPK1 (from CP024576.1) and of strains \#5707 and \#5920 (this work) allowed the identification of the attachment site $(a t t B)$ in the bacterial genome as it is duplicated upon the integration of the phage genome. Thus, the identical attachment site sequences are present in both the phage and the host genomes. The phage-encoded integrase enzyme, with the aid of a special host protein, catalyzes site-specific recombination, i.e., the physical exchange of viral and bacterial DNA strands Figure 6). The circular phage DNA is thereby integrated into the host genome as a linear prophage. Comparison of the phage sequences to the genome sequence of A. baumannii AbPK1 revealed that the attachment site sequence is a 22-bp sequence 5'-AAAAAGCGCTCAATCTAGAGCG-3', located in the phage genome upstream of the predicted tyrosine family integrase encoding gene (Figure 4). This sequence was described as target site duplication (TSD) in the A. baumannii AbPK1 genome [60]. Identical attB sites were also identified from the lysogenic strains \#5707 and \#5920.

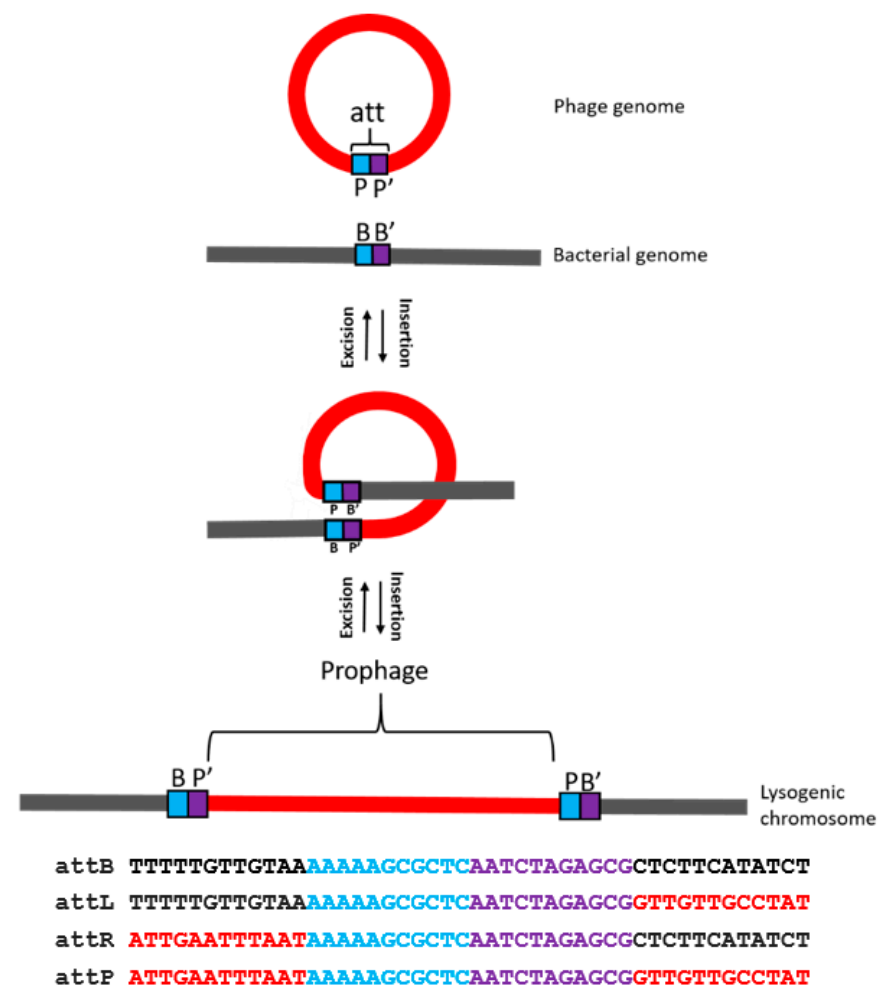

Figure 6. The prophage (red), flanked by att $L$ and attR upon insertion into A. baumannii genome (black). The attachment site in blue and violet [AAAAAGCGCTCAATCTAGAGCG] is the cross-over site for phage integration and excision.

To provide experimental evidence of the temperate nature of the phages, phage fEg-Aba01 resistant derivatives, i.e., potential lysogens, of A. baumannii strain \#6597 were isolated from fEg-Aba01 -infected bacterial lawns. PCR using phage-specific and att-site flanking primers (Table S2, Figure S2) was used to detect the presence of prophage in the lysogen candidates (Table S5). All the candidates proved to be positive confirming the temperate nature of the phage.

\section{Discussion}

We present here our findings suggesting that the three isolated $A$. baumannii siphophages were very likely prophages induced spontaneously during the culture of the lysogenic strains \#5707 and 
\#5920. As there is only limited information of the biological properties of temperate A. baumannii phages we present here a detailed characterization of the phages, and show experimentally that the prophages in \#5707 and \#5920 can be induced, and on the other hand that the phages can lysogenize a non-lysogenic strain. This indicated that the phages are fully functional. It is worth noting that these two lysogenic strains, in addition to sharing their MLST and capsule types, carry almost identical prophages, therefore either of them or both could be the original host of the isolated temperate phages. Comparison of the phage and prophage sequences demonstrated that they were almost 100\% identical differing only by a few occurrences of substitutions/deletions/insertions (Figure S5). It is, therefore, very likely that some of the mutations took place during the laboratory propagation of the phages as none of the three were fully identical to the prophage sequences in strains \#5707 and \#5920 (Figure S5). Based on the whole-genome VICTOR phylogenetic prediction (Figure S5A) it is apparent that fLi-Aba02 is closest to the prophages of \#5707 and \#5920, followed by fLi-Aba03, leaving fEg-Aba01 as most distant. Of special interest is the deletion/gene fusion in fEg-Aba01 (RoD-02, Table 3), that potentially could affect the phage biology. The deleted sequence carries the gene predicted to encode a peptidoglycan hydrolase ( $\mathrm{g} 19$ of fLi-Aba02 and fLi-Aba03) that might be involved in the lysis of the bacterial cell and the release of the phage progeny. This deletion seems to be well tolerated as we observed no gross differences between the three phages. The same applied apparently to the other major differences in fEg-Aba01 affected genes $g 48$ and $g 28 c$ (RoD-05 and RoD-07), truncating both from the $3^{\prime}$-end. This short-term evolution of the phages allows identification of non-essential regions of the phage genomes.

When isolating the phages, among the 20 clinical A. baumannii strains was one, \#6597 that was sensitive to the phages and made their detection possible. Interestingly, among the 53 Acinetobacter strains representing 7 species in addition to A. baumannii, only two $A$. baumannii strains were sensitive to the phages. This narrow host range could be due to several different reasons: (i) the phage receptor structures (LOS, capsule or outer membrane proteins) of the strains are different, (ii) the strains might be lysogens similar to \#5707 and \#5920, (iii) other resident prophages may encode an infection exclusion system or (iv) the presence of phage-specific spacers in the CRISPR/Cas locus [76]. The fact that all the strains shared the LOS type, and that the phage-sensitive strain \#6597 represents capsule type KL3 (Table 4) makes it likely that the phages are KL3 specific. There is a discrepancy; the temperate phages infect only the KL3 strain but reside as prophages in KL25 strain. The structures of the KL3 and KL25 capsule polysaccharides are completely different $[77,78]$, thus, one can ask the question how they entered in the first place into the KL25 strain. One can entertain two scenarios. First, if the phage receptor is indeed KL3, then the prophage should have entered the KL25 lineage before they have taken up the KL25 capsule gene cluster, or alternatively, the prophage has been transduced by a KL25 specific phage, or second, the phage receptor is not the KL3 capsule but an outer membrane protein. The fact that the phage plaque is surrounded by a halo, indicates that a diffusible enzymatic activity, likely associated with the phage tail, is degrading the capsular polysaccharide around the plaque, indirectly indicating that the KL3 capsule is specifically recognized by the phage. This question remains to be addressed in future.

The phages were morphologically typical siphoviruses with heads of about $60 \mathrm{~nm}$ in diameter, and flexible non-contractile tails of 140-150 nm in length, the genomes 33.8-35.0 kb in size encoding 52-54 predicted genes. We identified the attP sequence of the phage, and demonstrated experimentally that the phage has cohesive termini that the PhageTerm tool predicted to be $10 \mathrm{nt}$ long (Figure S3). The adsorption curves of the phages (Figure 2) demonstrated that the phages adsorb to the bacteria extremely rapidly and efficiently with $>95 \%$ of phages adsorbed already at the first time point of $1 \mathrm{~min}$.

Several genomic data screening studies have been carried out to identify prophages that indeed turn out to be very abundant in A. baumannii genomes [33,61,79]. It is apparent that many of the identified prophages may also be involved in horizontal gene transfer and may carry genes encoding antibiotic resistance or virulence factors [79], however, this was not the case with the prophages identified in this work. Of note, the gene claimed to encode sialic acid acetyltransferase 3 in GI5 of 
AbPK1 [60] was here based on HHpred search annotated as acetylxylan esterase like protein (Gp19), thus a hydrolase, so it very likely may have a function in capsule degradation. While spontaneous induction of the prophages as described in the present study has not been reported earlier, prophage induction using mitomycin $C$ has been reported [33,79]. Similarly, the phage vB_AbaS_TRS1, a 40.7 kb siphovirus, was induced by mitomycin C treatment from the A. baumannii strain A118 culture [80], however, it did not show any similarity to $\mathrm{fEg}$-Aba01 and the other phages described here. On the other hand, based on the $>99 \%$ identity of prophage GI5 of AbPK1 is very likely that it would behave identically to the spontaneously inducible phages described in this work.

As temperate phages are not considered suitable for phage therapy, non-lysogenic derivatives of the isolated phages could be constructed in future by targeted deletion of the lysogen decision gene cluster, similar to the strategy used in the recent Mycobacterium abscessus phage treatment case [81], provided that the selected phages do not carry any harmful genes. This could be worthwhile if there are difficulties in isolating Acinetobacter phages that we have experienced in Finland, and as the adsorption curves of the phages showed extraordinary adsorption rates suggesting also high efficiency in killing the target bacteria [82].

Supplementary Materials: The following are available online at http://www.mdpi.com/1999-4915/12/6/604/s1, Figure S1: plaque morphology of fEg-Aba01. Figure S2: schematic representation of the primers used to confirm the presence of the prophage in bacterial genomes. $\mathrm{B}, \mathrm{B}^{\prime}, \mathrm{P}$ and $\mathrm{P}^{\prime}$ represent the bacterial and phage attachment site sequences. Figure S3: restriction digestion analysis of phages fEg-Aba01 and fLi-Aba02 digested with 8 different enzymes demonstrating the $>99 \%$ sequence identity of the phages. Figure S4: PhageTerm analysis of the fEg-Aba01 sequence read data demonstrating the presence of HK97 type 10 nt long 3' cohesive ends. Figure S5: comparison of the of the nucleotide sequences of the three temperate Acinetobacter phages and the prophage loci of A. baumannii strains AbPK1, \#5707 and \#5920. Figure S6: BLASTN alignment of the prophage of A. baumannii strain AbPK1 against the whole genome de novo assembly contigs of strains \#5707, \#5907, \#5920, and \#6597. The ABPK1 sequence contained short prophage-flanking sequences up- and down-stream of the prophage. While \#6597 completely lacks the prophage, it is completely present in \#5707 and \#5920, and partially in \#5907. Table S1: bacterial strains used in the work. Table S2: oligonucleotide primers used for PCR in the work. Table S3: annotations and comparisons of the phage and prophage gene products. Table S4: detection of prophage specific sequences by PCR in the clinical strains used for phage enrichment using prophage-specific primer pairs. Table S5: detection of prophage sequences in lysogens by PCR.

Author Contributions: Conceptualization, S.B., M.I.P. and M.S.; methodology, S.B. and M.I.P.; formal analysis, S.B., M.I.P. and M.S.; investigation, S.B., M.I.P. and M.S.; resources, J.H., Z.A.M.B., M.I.A.-D., A.K.A.E.-S., and M.S.; writing —original draft preparation, S.B. and M.S.; writing-review and editing, S.B., J.H., M.I.P., Z.A.M.B., M.I.A.-D, A.K.A.E.-S., and M.S.; visualization, S.B. and M.S.; supervision, Z.A.M.B., M.I.A.-D, A.K.A.E.-S., and M.S.; funding acquisition, Z.A.M.B., and M.S. All authors have read and agreed to the published version of the manuscript

Funding: This research was funded by Damietta University to S.B. and by the Academy of Finland (project 288701) and Jane and Aatos Erkko Foundation grants to M.S. Open access funding provided by University of Helsinki.

Acknowledgments: S.B. is grateful for the advice and support she received from the other members of the Skurnik lab, and Ms. Mervi Lindman for training and help with EM. She wants especially thank Liisa Penttilä for the help in organizing everyday life in Finland. We are grateful to Christine Rohde and Johannes Wittmann (German Collection of Microorganisms and Cell Cultures $\mathrm{GmbH}$ ) for sending us the A. baumannii strain DSM 106838.

Conflicts of Interest: The authors declare no conflict of interest. The funders had no role in the design of the study; in the collection, analyses, or interpretation of data; in the writing of the manuscript, or in the decision to publish the results.

\section{References}

1. Bergogne-Berezin, E.; Towner, K.J. Acinetobacter spp. as nosocomial pathogens: Microbiological, clinical, and epidemiological features. Clin. Microb. Rev. 1996, 9, 148-165. [CrossRef]

2. Peleg, A.Y.; Seifert, H.; Paterson, D.L. Acinetobacter baumannii: Emergence of a successful pathogen. Clin. Microbiol. Rev. 2008, 21, 538-582. [CrossRef] [PubMed]

3. Davis, K.A.; Moran, K.A.; McAllister, C.K.; Gray, P.J. Multidrug-resistant Acinetobacter extremity infections in soldiers. Emerg. Infect. Dis. 2005, 11, 1218-1224. [CrossRef] [PubMed] 
4. Abbott, I.; Cerqueira, G.M.; Bhuiyan, S.; Peleg, A.Y. Carbapenem resistance in Acinetobacter baumannii: Laboratory challenges, mechanistic insights and therapeutic strategies. Expert Rev. Anti-Infect. Ther. 2013, 11, 395-409. [CrossRef] [PubMed]

5. Dijkshoorn, L.; Nemec, A.; Seifert, H. An increasing threat in hospitals: Multidrug-resistant Acinetobacter baumannii. Nat. Rev. Microbiol. 2007, 5, 939-951. [CrossRef]

6. Magiorakos, A.P.; Srinivasan, A.; Carey, R.B.; Carmeli, Y.; Falagas, M.E.; Giske, C.G.; Harbarth, S.; Hindler, J.F.; Kahlmeter, G.; Olsson-Liljequist, B.; et al. Multidrug-resistant, extensively drug-resistant and pandrug-resistant bacteria: An international expert proposal for interim standard definitions for acquired resistance. Clin. Microbiol. Infect. 2012, 18, 268-281. [CrossRef]

7. Wand, M.E.; Bock, L.J.; Bonney, L.C.; Sutton, J.M. Retention of virulence following adaptation to colistin in Acinetobacter baumannii reflects the mechanism of resistance. J. Antimicrob. Chemother. 2015, 70, 2209-2216. [CrossRef]

8. Cai, Y.; Chai, D.; Wang, R.; Liang, B.B.; Bai, N. Colistin resistance of Acinetobacter baumannii: Clinical reports, mechanisms and antimicrobial strategies. J. Antimicrob. Chemother. 2012, 67, 1607-1615. [CrossRef]

9. Nordmann, P.; Poirel, L. Emerging carbapenemases in Gram-negative aerobes. Clin. Microbiol. Infect. 2002, 8, 321-331. [CrossRef]

10. Burrowes, B.; Harper, D.R.; Anderson, J.; McConville, M.; Enright, M.C. Bacteriophage therapy: Potential uses in the control of antibiotic-resistant pathogens. Expert Rev. Anti-Infect. Ther. 2011, 9, 775-785. [CrossRef]

11. Parisien, A.; Allain, B.; Zhang, J.; Mandeville, R.; Lan, C.Q. Novel alternatives to antibiotics: Bacteriophages, bacterial cell wall hydrolases, and antimicrobial peptides. J. Appl. Microbiol. 2008, 104, 1-13. [CrossRef] [PubMed]

12. Hua, Y.; Luo, T.; Yang, Y.; Dong, D.; Wang, R.; Wang, Y.; Xu, M.; Guo, X.; Hu, F.; He, P. Phage Therapy as a Promising New Treatment for Lung Infection Caused by Carbapenem-Resistant Acinetobacter baumannii in Mice. Front. Microbiol. 2017, 8, 2659. [CrossRef] [PubMed]

13. Regeimbal, J.M.; Jacobs, A.C.; Corey, B.W.; Henry, M.S.; Thompson, M.G.; Pavlicek, R.L.; Quinones, J.; Hannah, R.M.; Ghebremedhin, M.; Crane, N.J.; et al. Personalized therapeutic cocktail of wild environmental phages rescues mice from Acinetobacter baumannii wound infections. Antimicrob. Agents Chemother. 2016, 60, 5806-5816. [CrossRef] [PubMed]

14. LaVergne, S.; Hamilton, T.; Biswas, B.; Kumaraswamy, M.; Schooley, R.T.; Wooten, D. Phage therapy for a multidrug-resistant Acinetobacter baumannii craniectomy site infection. Open Forum Infect. Dis. 2018, 5, ofy064. [CrossRef] [PubMed]

15. Schooley, R.T.; Biswas, B.; Gill, J.J.; Hernandez-Morales, A.; Lancaster, J.; Lessor, L.; Barr, J.J.; Reed, S.L.; Rohwer, F.; Benler, S.; et al. Development and use of personalized bacteriophage-based therapeutic cocktails to treat a patient with a disseminated resistant Acinetobacter baumannii Infection. Antimicrob. Agents Chemother. 2017, 61, e00954-17. [CrossRef] [PubMed]

16. Abedon, S.T.; Kuhl, S.J.; Blasdel, B.G.; Kutter, E.M. Phage treatment of human infections. Bacteriophage 2011, 1, 66-85. [CrossRef]

17. Garcia, P.; Monjardin, C.; Martin, R.; Madera, C.; Soberon, N.; Garcia, E.; Meana, A.; Suarez, J.E. Isolation of new Stenotrophomonas bacteriophages and genomic characterization of temperate phage S1. Appl. Environ. Microbiol. 2008, 74, 7552-7560. [CrossRef]

18. Adams, M.H. Bacteriophages; Interscience Publishers: New York, NY, USA, 1959.

19. Ackermann, H.W. Phage classification and characterization. Methods Mol. Biol. 2009, 501, 127-140.

20. Adriaenssens, E.M.; Sullivan, M.B.; Knezevic, P.; van Zyl, L.J.; Sarkar, B.L.; Dutilh, B.E.; Alfenas-Zerbini, P.; Lobocka, M.; Tong, Y.; Brister, J.R.; et al. Taxonomy of prokaryotic viruses: 2018-2019 update from the ICTV Bacterial and Archaeal Viruses Subcommittee. Arch. Virol. 2020, 165, 1253-1260. [CrossRef]

21. Skurnik, M.; Strauch, E. Phage therapy: Facts and fiction. Int. J. Med. Microbiol. 2006, 296, 5-14. [CrossRef]

22. Shao, Q.; Trinh, J.T.; Zeng, L. High-resolution studies of lysis-lysogeny decision-making in bacteriophage lambda. J. Biol. Chem. 2019, 294, 3343-3349. [CrossRef] [PubMed]

23. Feiner, R.; Argov, T.; Rabinovich, L.; Sigal, N.; Borovok, I.; Herskovits, A.A. A new perspective on lysogeny: Prophages as active regulatory switches of bacteria. Nat. Rev. Microbiol. 2015, 13, 641-650. [CrossRef] [PubMed]

24. Bobay, L.M.; Rocha, E.P.; Touchon, M. The adaptation of temperate bacteriophages to their host genomes. Mol. Biol. Evol. 2013, 30, 737-751. [CrossRef] [PubMed] 
25. Cuenca Mdel, S.; Molina-Santiago, C.; Gomez-Garcia, M.R.; Ramos, J.L. A Pseudomonas putida double mutant deficient in butanol assimilation: A promising step for engineering a biological biofuel production platform. FEMS Microbiol. Lett. 2016, 363, fnw018. [CrossRef]

26. Boyd, E.F. Bacteriophage-encoded bacterial virulence factors and phage-pathogenicity island interactions. Adv. Virus Res. 2012, 82, 91-118.

27. Chen, Y.; Yang, L.; Yang, D.; Song, J.; Wang, C.; Sun, E.; Gu, C.; Chen, H.; Tong, Y.; Tao, P.; et al. Specific Integration of Temperate Phage Decreases the Pathogenicity of Host Bacteria. Front. Cell. Infect. Microbiol. 2020, 10, 14. [CrossRef]

28. Snitkin, E.S.; Zelazny, A.M.; Montero, C.I.; Stock, F.; Mijares, L.; Program, N.C.S.; Murray, P.R.; Segre, J.A. Genome-wide recombination drives diversification of epidemic strains of Acinetobacter baumannii. Proc. Natl. Acad. Sci. USA 2011, 108, 13758-13763. [CrossRef]

29. Edlin, G.; Lin, L.; Bitner, R. Reproductive Fitness of P1, P2, and Mu-Lysogens of Escherichia coli. J. Virol. 1977, 21, 560-564. [CrossRef]

30. Shaikh, N.; Tarr, P.I. Escherichia coli O157: H7 shiga toxin-encoding bacteriophages: Integrations, excisions, truncations, and evolutionary implications. J. Bacteriol. 2003, 185, 6495. [CrossRef]

31. Wang, X.X.; Kim, Y.; Ma, Q.; Hong, S.H.; Pokusaeva, K.; Sturino, J.M.; Wood, T.K. Cryptic prophages help bacteria cope with adverse environments. Nat. Commun. 2010, 1, 147. [CrossRef]

32. Mahony, J.; McGrath, S.; Fitzgerald, G.F.; van Sinderen, D. Identification and Characterization of Lactococcal-Prophage-Carried Superinfection Exclusion Genes. Appl. Environ. Microbiol. 2008, 74, 6206-6215. [CrossRef] [PubMed]

33. Costa, A.R.; Monteiro, R.; Azeredo, J. Genomic analysis of Acinetobacter baumannii prophages reveals remarkable diversity and suggests profound impact on bacterial virulence and fitness. Sci. Rep. 2018, 8, 15346. [CrossRef] [PubMed]

34. Summers, W.C. Bacteriophage therapy. Annu. Rev. Microbiol. 2001, 55, 437-451. [CrossRef] [PubMed]

35. Jonczyk, E.; Klak, M.; Miedzybrodzki, R.; Gorski, A. The influence of external factors on bacteriophages-review. Folia Microbiol. 2011, 56, 191-200. [CrossRef] [PubMed]

36. Bertani, G. Lysogeny at mid-twentieth century: P1, P2, and other experimental, systems. J. Bacteriol. 2004, 186, 595-600. [CrossRef] [PubMed]

37. Baker, P.M.; Farmer, J.J. New Bacteriophage-Typing System for Yersinia enterocolitica, Yersinia kristensenii, Yersinia frederiksenii, and Yersinia intermedia: Correlation with serotyping, biotyping, and antibiotic susceptibility. J. Clin. Microbiol. 1982, 15, 491-502. [CrossRef]

38. Lin, N.T.; Chiou, P.Y.; Chang, K.C.; Chen, L.K.; Lai, M.J. Isolation and characterization of phi AB2: A novel bacteriophage of Acinetobacter baumannii. Res. Microbiol. 2010, 161, 308-314. [CrossRef]

39. Jamalludeen, N.; Johnson, R.P.; Friendship, R.; Kropinski, A.M.; Lingohr, E.J.; Gyles, C.L. Isolation and characterization of nine bacteriophages that lyse O149 enterotoxigenic Escherichia coli. Vet. Microbiol. 2007, 124, 47-57. [CrossRef]

40. Karumidze, N.; Kusradze, I.; Rigvava, S.; Goderdzishvili, M.; Rajakumar, K.; Alavidze, Z. Isolation and Characterisation of Lytic Bacteriophages of Klebsiella pneumoniae and Klebsiella oxytoca. Curr. Microbiol. 2013, 66, 251-258. [CrossRef]

41. Oliveira, A.; Sillankorva, S.; Quinta, R.; Henriques, A.; Sereno, R.; Azeredo, J. Isolation and characterization of bacteriophages for avian pathogenic E. coli strains. J. Appl. Microbiol. 2009, 106, 1919-1927. [CrossRef]

42. Pickard, D.J. Preparation of bacteriophage lysates and pure DNA. Methods Mol. Biol. 2009, 502, 3-9. [PubMed]

43. Sambrook, J.; Russell, D.W. Molecular Cloning: A Laboratory Manual, 3rd ed.; Cold Spring Harbor Laboratory: Cold Spring Harbor, NY, USA, 2001.

44. Sambrook, J.; Russell, D.W. Purification of Bacteriophage $\lambda$ Particles by Centrifugation through a Glycerol Step Gradient. CSH Protoc. 2006, 2006. [CrossRef] [PubMed]

45. Kwiatek, M.; Mizak, L.; Parasion, S.; Gryko, R.; Olender, A.; Niemcewicz, M. Characterization of five newly isolated bacteriophages active against Pseudomonas aeruginosa clinical strains. Folia Microbiol. 2015, 60, 7-14. [CrossRef] [PubMed]

46. Prestinaci, F.; Pezzotti, P.; Pantosti, A. Antimicrobial resistance: A global multifaceted phenomenon. Pathog. Glob. Health 2015, 109, 309-318. [CrossRef] 
47. Carver, T.; Berriman, M.; Tivey, A.; Patel, C.; Bohme, U.; Barrell, B.G.; Parkhill, J.; Rajandream, M.A. Artemis and ACT: Viewing, annotating and comparing sequences stored in a relational database. Bioinformatics 2008, 24, 2672-2676. [CrossRef]

48. Carver, T.; Harris, S.R.; Berriman, M.; Parkhill, J.; McQuillan, J.A. Artemis: An integrated platform for visualization and analysis of high-throughput sequence-based experimental data. Bioinformatics 2012, 28, 464-469. [CrossRef]

49. Kearse, M.; Moir, R.; Wilson, A.; Stones-Havas, S.; Cheung, M.; Sturrock, S.; Buxton, S.; Cooper, A.; Markowitz, S.; Duran, C.; et al. Geneious Basic: An integrated and extendable desktop software platform for the organization and analysis of sequence data. Bioinformatics 2012, 28, 1647-1649. [CrossRef]

50. Aziz, R.K.; Bartels, D.; Best, A.A.; DeJongh, M.; Disz, T.; Edwards, R.A.; Formsma, K.; Gerdes, S.; Glass, E.M.; Kubal, M.; et al. The RAST server: Rapid annotations using subsystems technology. BMC Genom. 2008, 9, 75. [CrossRef]

51. Garneau, J.R.; Depardieu, F.; Fortier, L.C.; Bikard, D.; Monot, M. PhageTerm: A tool for fast and accurate determination of phage termini and packaging mechanism using next-generation sequencing data. Sci. Rep. 2017, 7, 8292. [CrossRef]

52. Alva, V.; Nam, S.Z.; Soding, J.; Lupas, A.N. The MPI bioinformatics Toolkit as an integrative platform for advanced protein sequence and structure analysis. Nucleic Acids Res. 2016, 44, W410-W415. [CrossRef]

53. Kallio, M.A.; Tuimala, J.T.; Hupponen, T.; Klemela, P.; Gentile, M.; Scheinin, I.; Koski, M.; Kaki, J.; Korpelainen, E.I. Chipster: User-friendly analysis software for microarray and other high-throughput data. BMC Genom. 2011, 12, 507. [CrossRef] [PubMed]

54. Katoh, K.; Standley, D.M. MAFFT Multiple Sequence Alignment Software Version 7: Improvements in Performance and Usability. Mol. Biol. Evol. 2013, 30, 772-780. [CrossRef] [PubMed]

55. Kumar, S.; Stecher, G.; Li, M.; Knyaz, C.; Tamura, K. MEGA X: Molecular Evolutionary Genetics Analysis across Computing Platforms. Mol. Biol. Evol. 2018, 35, 1547-1549. [CrossRef] [PubMed]

56. Meier-Kolthoff, J.P.; Goker, M. VICTOR: Genome-based phylogeny and classification of prokaryotic viruses. Bioinformatics 2017, 33, 3396-3404. [CrossRef]

57. Wyres, K.L.; Cahill, S.M.; Holt, K.E.; Hall, R.M.; Kenyon, J.J. Identification of Acinetobacter baumannii loci for capsular polysaccharide (KL) and lipooligosaccharide outer core (OCL) synthesis in genome assemblies using curated reference databases compatible with Kaptive. Microb. Genom. 2020, 6, e000339. [CrossRef]

58. Goffartroskam, J. Quantitative study of sensitive and lysogenic bacteria surviving infection of a Staphylococcus by a temperate bacteriophage. Antonie Leeuwenhoek 1965, 31, 249-261. [CrossRef]

59. Bae, T.; Baba, T.; Hiramatsu, K.; Schneewind, O. Prophages of Staphylococcus aureus Newman and their contribution to virulence. Mol. Microbiol. 2006, 62, 1035-1047. [CrossRef]

60. Linz, B.; Mukhta, N.; Shabbir, M.Z.; Rivera, I.; Ivanov, Y.V.; Tahir, Z.; Yaqub, T.; Harvill, E.T. Virulent Epidemic Pneumonia in Sheep Caused by the Human Pathogen Acinetobacter baumannii. Front. Microbiol. 2018, 9, 9. [CrossRef]

61. Hare, J.M.; Ferrell, J.C.; Witkowski, T.A.; Grice, A.N. Prophage induction and differential RecA and UmuDAb transcriptome regulation in the DNA damage responses of Acinetobacter baumannii and Acinetobacter baylyi. PLoS ONE 2014, 9, e93861. [CrossRef]

62. Stark, W.M. Making serine integrases work for us. Curr. Opin. Microbiol. 2017, 38, 130-136. [CrossRef]

63. Yoshida, M.; Yoshida-Takashima, Y.; Nunoura, T.; Takai, K. Genomic characterization of a temperate phage of the psychrotolerant deep-sea bacterium Aurantimonas sp. Extremophiles 2015, 19, 49-58. [CrossRef] [PubMed]

64. Chen, Y.; Narendra, U.; Iype, L.E.; Cox, M.M.; Rice, P.A. Crystal structure of a Flp recombinase-Holliday junction complex: Assembly of an active oligomer by helix swapping. Mol. Cell 2000, 6, 885-897. [CrossRef]

65. Sherratt, D.J.; Soballe, B.; Barre, F.X.; Filipe, S.; Lau, I.; Massey, T.; Yates, J. Recombination and chromosome segregation. Philos. Trans. R. Soc. B Biol. Sci. 2004, 359, 61-69. [CrossRef] [PubMed]

66. Van Duyne, G.D. A structural view of cre-loxp site-specific recombination. Annu. Rev. Biophys. Biomol. Struct. 2001, 30, 87-104. [CrossRef]

67. Barer, M.R.; Harwood, C.R. Bacterial viability and culturability. Adv. Microb. Physiol. 1999, 41, $93-137$.

68. Cleverley, R.M.; Rutter, Z.J.; Rismondo, J.; Corona, F.; Tsui, H.T.; Alatawi, F.A.; Daniel, R.A.; Halbedel, S.; Massidda, O.; Winkler, M.E.; et al. The cell cycle regulator GpsB functions as cytosolic adaptor for multiple cell wall enzymes. Nat. Commun. 2019, 10, 261. [CrossRef] 
69. Lionnet, T.; Spiering, M.M.; Benkovic, S.J.; Bensimon, D.; Croquette, V. Real-time observation of bacteriophage T4 gp41 helicase reveals an unwinding mechanism. Proc. Natl. Acad. Sci. USA 2007, 104, 19790-19795. [CrossRef]

70. Mitsunobu, H.; Zhu, B.; Lee, S.J.; Tabor, S.; Richardson, C.C. Flap endonuclease of bacteriophage T7: Possible roles in RNA primer removal, recombination and host DNA breakdown. Bacteriophage 2014, 4, e28507. [CrossRef]

71. Shi, J.; Gao, X.; Tian, T.; Yu, Z.; Gao, B.; Wen, A.; You, L.; Chang, S.; Zhang, X.; Zhang, Y.; et al. Structural basis of Q-dependent transcription antitermination. Nat. Commun. 2019, 10, 2925. [CrossRef]

72. Duffy, C.; Feiss, M. The large subunit of bacteriophage $\lambda$ 's terminase plays a role in DNA translocation and packaging termination. J. Mol. Biol. 2002, 316, 547-561. [CrossRef]

73. Rajagopala, S.V.; Casjens, S.; Uetz, P. The protein interaction map of bacteriophage lambda. BMC Microbiol. 2011, 11, 213. [CrossRef] [PubMed]

74. Katsura, I.; Hendrix, R.W. Length determination in bacteriophage lambda tails. Cell 1984, 39, 691-698. [CrossRef]

75. Kropinski, A.M.; Waddell, T.; Meng, J.; Franklin, K.; Ackermann, H.W.; Ahmed, R.; Mazzocco, A.; Yates, J., 3rd; Lingohr, E.J.; Johnson, R.P. The host-range, genomics and proteomics of Escherichia coli O157:H7 bacteriophage rV5. Virol. J. 2013, 10, 76. [CrossRef] [PubMed]

76. Dedrick, R.M.; Jacobs-Sera, D.; Bustamante, C.A.; Garlena, R.A.; Mavrich, T.N.; Pope, W.H.; Reyes, J.C.; Russell, D.A.; Adair, T.; Alvey, R.; et al. Prophage-mediated defence against viral attack and viral counter-defence. Nat. Microbiol. 2017, 2, 16251. [CrossRef] [PubMed]

77. MacLean, L.L.; Perry, M.B.; Chen, W.; Vinogradov, E. The structure of the polysaccharide O-chain of the LPS from Acinetobacter baumannii strain ATCC 17961. Carbohydr. Res. 2009, 344, 474-478. [CrossRef]

78. Senchenkova, S.N.; Shashkov, A.S.; Popova, A.V.; Shneider, M.M.; Arbatsky, N.P.; Miroshnikov, K.A.; Volozhantsev, N.V.; Knirel, Y.A. Structure elucidation of the capsular polysaccharide of Acinetobacter baumannii AB5075 having the KL25 capsule biosynthesis locus. Carbohydr. Res. 2015, 408, 8-11. [CrossRef]

79. Lopez-Leal, G.; Santamaria, R.I.; Cevallos, M.A.; Gonzalez, V.; Castillo-Ramirez, S. Prophages encode antibiotic resistance genes in Acinetobacter baumannii. Microb. Drug Resist. 2020. [CrossRef]

80. Turner, D.; Wand, M.E.; Sutton, J.M.; Centron, D.; Kropinski, A.M.; Reynolds, D.M. Genome sequence of vB_AbaS_TRS1, a viable prophage isolated from acinetobacter baumannii strain A118. Genome Announc. 2016, 4, 4. [CrossRef]

81. Dedrick, R.M.; Guerrero-Bustamante, C.A.; Garlena, R.A.; Russell, D.A.; Ford, K.; Harris, K.; Gilmour, K.C.; Soothill, J.; Jacobs-Sera, D.; Schooley, R.T.; et al. Engineered bacteriophages for treatment of a patient with a disseminated drug-resistant Mycobacterium abscessus. Nat. Med. 2019, 25, 730-733. [CrossRef]

82. Abedon, S.T. Phage therapy dosing: The problem(s) with multiplicity of infection (MOI). Bacteriophage 2016, 6, e1220348. [CrossRef]

(C) 2020 by the authors. Licensee MDPI, Basel, Switzerland. This article is an open access article distributed under the terms and conditions of the Creative Commons Attribution (CC BY) license (http://creativecommons.org/licenses/by/4.0/). 